\title{
Distributed health literacy among people living with type 2 diabetes in Portugal: Defining levels of awareness and support
}

\author{
Liliana Abreu MA (10) ${ }^{1,2,3}$ | João Arriscado Nunes PhD ${ }^{4}$ | Peter Taylor PhD ${ }^{5}$ | \\ Susana Silva $\mathrm{PhD}^{2,3}$
}

${ }^{1}$ i3S-Instituto de Investigação e Inovação em Saúde, Universidade do Porto, Porto, Portugal

${ }^{2}$ ISPUP-EPIUnit, Instituto de Saúde

Pública, Universidade do Porto, Porto,

Portugal

${ }^{3}$ Faculdade de Medicina, Universidade do

Porto, Porto, Portugal

${ }^{4}$ Center for Social Studies \& School of Economics of the University of Coimbra, Coimbra, Portugal

${ }^{5}$ Science, Technology \& Values

Program, University of Massachusetts, Boston, MA, USA

\section{Correspondence}

Liliana Abreu, i3S Instituto de Inovação e Investigação em Saúde, Universidade do Porto, Porto, Portugal.

Email: liliana.abreu@ibmc.up.pt

\section{Funding}

This research was supported by FEDER funding from the Operational Program Factors of Competitiveness-COMPETE and by national funding from the FCT-Foundation for Science and Technology (Portuguese Ministry of Education and Science) within the grants SFRH/BD/78949/2011 (to L.A.), and IF/01674/2015 (to S.S.).

\begin{abstract}
This study embraces a patient-centred and narrative-oriented notion of health literacy, exploring how social networks and personal experiences constitute distributed health literacy (DHL) by mapping out health literacy mediators of each individual and how they enable self-management skills and knowledge of health conditions. Semistructured interviews with 26 patients with type 2 diabetes were conducted in a Primary Care Center of Porto (Portugal) from October 2014 to December 2015. Data were collected based on McGill Illness Narrative Interview (MINI). Following the grounded theory, interviews were analysed as case-based and process-tracingoriented. Three awareness narratives emerged: (i) a narrative of minimisation revealing minimal impact of diabetes in patients' lives and daily routines, resignation towards "inevitable" consequences of the diagnosis and dependence of a large network of health literacy mediators; (ii) a narrative of empathy, where patients tended to mention readjustments in their lives by following medical recommendations regarding medication without criticism and with few health literacy mediators; (iii) a narrative of disruption, with patients highlighting the huge impact of diabetes on their lives and their individual responsibility and autonomy with respect to the management of diabetes and the search for alternatives to medication, relying on a very restrictive network of mediators. Exploring meanings given to diagnosis, identifying health mediators and analysing the structure of social networks can contribute to understand the distributed nature of health literacy. Assessing DHL can assist health professionals and those providing care in the community in promoting health literacy and providing models for a more patient-centred health system.
\end{abstract}

\section{KEYWORDS}

distributed health literacy, health mediators, illness narratives, patient-centredness, social networks, type 2 diabetes

\section{1 | INTRODUCTION}

In recent years, practices of health education and communication have been challenged by findings connecting literacy to health. Addressing health literacy is a daunting task as it involves social and individual factors, mediated by education, culture and language, as well as individuals' social networks (Lee, Arozullah, \& Cho, 2004; Nielsen-Bohlman, 2004).

The published literature has been increasingly focused on how limited individual health literacy negatively affects patients' ability to understand health information, the communication with physicians, and compliance with recommendations and treatments (Clement, Ibrahim, 
Crichton, Wolf, \& Rowlands, 2009; Coulter, Parsons, \& Askham, 2008; Mantwill \& Schulz, 2015; Miller, 2016). If patients have difficulties in obtaining, processing and understanding basic health information, their capacity for self-care will be limited-a particularly critical aspect in chronic conditions such as type 2 diabetes (Williams et al., 1998), where $95 \%$ of illness management depends on the patient (Anderson, 1985; Russo \& Walker, 2001). Previous studies, however, have shown that some patients with lower scores on individual health literacy still keep diabetes under control (Osborn, Bains, \& Egede, 2010; Powell, Hill, \& Clancy, 2007). They may be able to manage their condition without fully understanding it, or rely on significant others-health "literacy mediators" e.g. caregivers, family, friends (Edwards, Wood, Davies, \& Edwards, 2013; Pooley, Gerrard, Morton, \& Astbury, 2001) or health professionals involved in routine clinical care (Baynham, 1995)-for managing the condition.

This paper examines the entanglement of individual skills and social support through the lenses of the concept of distributed health literacy (DHL)-defined as literacy dispersed throughout a group, including resources provided by a personal network of individuals and social media (Edwards, Wood, Davies, \& Edwards, 2012; Lepore, 1991). The paper focuses on how patients with type 2 diabetes draw on their social network for support with identified health literacy-related tasks. Our proposal goes beyond the focus on quantitative measurement of health literacy or on assessment of individual capacities of reading and comprehension and numeracy skills (Andrus \& Roth, 2002; Nutbeam, 2000; Williams et al., 1995). Instead, we explore the interactions between the demands of health systems and the skills of individuals, as well as the context and complexity of skills and support identified as necessary for patients to be considerate "literate" in relation to their health (Berkman, Davis, \& McCormack, 2010; Sørensen et al., 2012) .

The development of broader measures of health literacy, with deeper understanding of $\mathrm{DHL}$, may benefit from the analysis of illness narratives of patients with type 2 diabetes (Greenhalgh, 2009), in the sense that the point of view of lay experiences and "patienthood" may help unpack chronic illness self-management behaviour since diagnosis (Bury, 2001; Flyvbjerg, 2006), and self-management support (which has been identified as relatively underdeveloped in Europe; Elissen, Nolte, \& Knai, 2013; Kousoulis et al., 2014; Foss et al., 2015). Analysing illness narratives that stem from diagnosis contributes to the theoretical approach of social construction of illness (Sontag, 1978), which has particular relevance for understanding DHL. This study embraces a patient-centred and narrative-oriented notion of health literacy, exploring how social networks and personal experiences are a portrait of the DHL, mapping out health literacy mediators for each individual, and how they enable self-management skills and knowledge of health conditions.

\section{2 | METHODS}

This is a qualitative and observational study. From October 2014 to December 2015, 31 people diagnosed with type 2 diabetes, attending a Primary Care Center in Porto District (Northern Portugal), were

\section{What is known about this topic}

- Current definitions of health literacy $(\mathrm{HL})$ with its quantitative measurement instruments leave a gap in understanding.

- Some patients with lower scores on individual HL still successfully keep conditions, such as diabetes, under control.

- Involvement of family and friends is advocated as one of the core dimensions of patient-centred care.

\section{What this paper adds}

- Social networks with high-density provides more emotional and instrumental support than do less dense networks.

- People-centred health systems need to focus on DHL rather than just emphasising individual health literacy.

- It is important to create hybrid spaces for dialogue between multiple mediators in each individual networks.

invited by doctors or nurses to participate in the study-26 accepted. Participants were purposively sampled to include people with a diagnosis for more and less than 10 years, men and women aged around or over 50 years. Heterogeneity sampling was used for maximum variation of views and experiences, until theoretical saturation was reached-the point when no new, significant data emerge from data analysis (Strauss \& Corbin, 1998).

Data were collected based on the McGill Illness Narrative Interview (MINI), previously applied in another Portuguese study about health knowledge of people with asthma and breast cancer (Abreu, BorlidoSantos, Vilar-Correia, \& Arriscado-Nunes, 2012). MINI is a semistructured ethnographic and theoretically driven interview schedule, designed to elicit narratives and status of health knowledge (Groleau, Young, \& Kirmayer, 2006), covering the following sections: (i) Initial Narrative-intentionally unstructured, allowing interviewees to tell their story in their own way and on their own terms; (ii) Prototypesmore structured, aiming to elicit narratives on prototypical experience of self and others; (iii) Explanatory models-causal type of reasoning; (iv) Help seeking and service utilisation-inviting the interviewee to a narrative of their experience with health services, treatment and hospitalisation; ( v) Impact of illness-aiming to explore if and how patients believe the illness has led to changes in their identity and way of life since its onset. Data were analysed to enable the identification of distinct groups of narratives about the experience of illness in relation to diabetes. For the purposes of this paper, two additional topic questions were addressed to explore the role of health mediators: "Do you usually go accompanied to the medical visits (if yes, by whom)? If we ask you to choose someone to help you in a health-related issue, who would you choose and why?" (it was stated to the patients they could mention more than one person). 
Interviews were conducted by the first author in a private room, ranging from 29 to $90 \mathrm{~min}$ (average $55 \mathrm{~min}$ ). All were taped, professionally transcribed verbatim and checked for accuracy.

Based on grounded theory (Charmaz, 1983; Bryant \& Charmaz, 2010), interviews were analysed as case-based and process-tracingoriented, by the first author, using NVivo 10 (QSR International, USA, 2013). Coding of participants' responses was discussed by three of the authors. Process-tracing was achieved through coding each interview to identify categories associated with the processes of interest, incorporating constant comparison of the coded interviews, and exploration of deviant cases.

The findings are reported below with verbatim anonymised quotes from interview transcripts translated by the authors.

All participants formalised their collaboration through a written informed consent. Ethics approval was granted by the Research Ethics Committee of the Institute of Public Health of the University of Porto.

\section{3 | RESULTS}

Three themes emerged from data analysis (Table 1): (i) dealing with the diagnosis; (ii) self-management skills; and (iii) health literacy mediators. After the classification of each interviewee's positioning in relation to these themes, participants were grouped according to the following narratives, determined by the response to diagnosis: (i) narrative of minimisation-patients claiming minimal impact of diabetes on their lives and daily routines; (ii) narrative of empathy-patients tending to follow medical recommendations without criticism; (iii) narrative of disruption-patients highlighting a huge impact of diabetes on their lives and their individual responsibility on illness self-management. Participants' characteristics are described in Table 2.

\section{1 | Group 1. Narrative of minimisation}

\subsection{1 | Dealing with the diagnosis}

Interviewees enacting a narrative of minimisation reveal a low impact of diabetes in their lives and daily routines, which remained "normal" after diagnosis, and minimise or disguise symptoms when telling their stories as a way to dismiss the seriousness of their condition. They appear to discount feelings of being different after diagnosis, in order to maintain pre-illness identity intact by means of two repertoires: (i) deletion, a narrative mechanism that suppresses the gravity of diabetes when resetting it as a condition equivalent to other "non-serious" conditions, such as high cholesterol or hypertension; and (ii) purification, reasserting the continuity of minimisation by dismissing the diagnosis of diabetes as a disruptive moment or by constructing diabetes as a family condition or as a result of stressful situations that could not be prevented:

TABLE 1 Themes and narratives

\begin{tabular}{|c|c|c|c|}
\hline & $\begin{array}{l}\text { Dealing with the diagnosis } \\
\text { (explores attitudes, trajectories } \\
\text { and levels of awareness and } \\
\text { knowledge) }\end{array}$ & $\begin{array}{l}\text { Self-management skills } \\
\text { (explores the access to health services and how } \\
\text { they manage diet, physical exercise and } \\
\text { medication) }\end{array}$ & $\begin{array}{l}\text { Health literacy mediators } \\
\text { (explores sources of support-formal, } \\
\text { informal or other; to types of } \\
\text { support-pragmatic, informational and } \\
\text { emotional. The actors, networks and } \\
\text { processes) }\end{array}$ \\
\hline $\begin{array}{l}\text { Narrative of } \\
\text { minimisation }\end{array}$ & $\begin{array}{l}\text { Acceptance of diagnosis as } \\
\text { inevitable. Do not know the } \\
\text { causes of diabetes. Diagnosis } \\
\text { sometimes does not lead to } \\
\text { medical intervention. }\end{array}$ & $\begin{array}{l}\text { Use of non-technical language, little or no } \\
\text { understanding of the health condition and no } \\
\text { interest in further information details. } \\
\text { Information provided by the doctor or other } \\
\text { health professional, they usually interact, is } \\
\text { enough to manage the condition. The idea of } \\
\text { searching more about diabetes outside the } \\
\text { medical consultation is often regarded as } \\
\text { mistrusting the doctor. }\end{array}$ & $\begin{array}{l}\text { Largest network of "literacy mediators": } \\
\text { facilitators from formal (health } \\
\text { professionals) and informal (relatives) } \\
\text { settings, the type of support is } \\
\text { mostly informational. }\end{array}$ \\
\hline $\begin{array}{l}\text { Narrative of } \\
\text { empathy }\end{array}$ & $\begin{array}{l}\text { Making sense of symptoms, } \\
\text { point causes for diabetes; give } \\
\text { advice to others. }\end{array}$ & $\begin{array}{l}\text { Display some understanding of health } \\
\text { information, use of a mix of technical and } \\
\text { non-technical language, know the name of } \\
\text { medications, although with some difficulties } \\
\text { of pronunciation and the purpose of each. } \\
\text { Maintain that they received enough } \\
\text { information about diabetes for their needs; } \\
\text { have a more active participation in treatment, } \\
\text { good relationship with doctors. }\end{array}$ & $\begin{array}{l}\text { Intermediate network of "literacy } \\
\text { mediators": mostly from formal } \\
\text { settings; type of support is informa- } \\
\text { tional and emotional. }\end{array}$ \\
\hline $\begin{array}{c}\text { Narrative of } \\
\text { disruption }\end{array}$ & $\begin{array}{l}\text { Diagnosis is biographical } \\
\text { disruptive, leading to an active } \\
\text { attitude to deal with diabetes }\end{array}$ & $\begin{array}{l}\text { Good to excellent understanding of health } \\
\text { information, use of appropriate technical } \\
\text { language, often more information about } \\
\text { condition and treatments available, searching } \\
\text { treatments outside the standard public health } \\
\text { system. }\end{array}$ & $\begin{array}{l}\text { Smallest network of "literacy } \\
\text { mediators": Tendency to be very } \\
\text { independent in the management of } \\
\text { diabetes, sources of support are } \\
\text { mainly the doctor and Internet. }\end{array}$ \\
\hline
\end{tabular}


TABLE 2 Participants' characteristics

\begin{tabular}{|c|c|c|c|c|c|}
\hline Name (alias) & Age & Educational level & $\begin{array}{l}\text { Household } \\
\text { composition }\end{array}$ & $\begin{array}{l}\text { Years since } \\
\text { diagnosis }\end{array}$ & $\begin{array}{l}\text { Diabetes in } \\
\text { the family }\end{array}$ \\
\hline \multicolumn{6}{|l|}{ Minimisation } \\
\hline Alice & 49 & Elementary & Husband & 5 & Yes \\
\hline Beatriz & 70 & Elementary & Alone & 31 & Yes \\
\hline Diana & 74 & Elementary & Husband & 31 & Yes \\
\hline Raquel & 54 & Elementary & $\begin{array}{l}\text { Husband and } \\
\text { daughter }\end{array}$ & 3 & Yes \\
\hline César & 67 & Elementary & Wife & 16 & Yes \\
\hline Gabriela & 75 & None & Husband & 21 & Yes \\
\hline Júlio & 57 & Secondary & Alone & 8 & Yes \\
\hline Irene & 48 & Elementary & Parents & 4 & Yes \\
\hline Hugo & 56 & Elementary & Wife & 9 & Yes \\
\hline Isabel & 71 & Elementary & Alone & $\begin{array}{l}\text { Do not } \\
\text { know }\end{array}$ & Yes \\
\hline Laura & 84 & None & Alone & 15 & No \\
\hline Lourenço & 54 & Elementary & $\begin{array}{l}\text { Wife and } \\
\text { daughter }\end{array}$ & $\begin{array}{l}\text { Do not } \\
\text { know }\end{array}$ & Yes \\
\hline \multicolumn{6}{|l|}{ Empathy } \\
\hline Carla & 75 & Elementary & Son & $>20$ & No \\
\hline Henrique & 78 & None & Wife & 21 & Yes \\
\hline José & 71 & Elementary & Alone & 11 & Yes \\
\hline Isaac & 77 & None & Alone & 21 & Yes \\
\hline Helena & 70 & Elementary & Husband & 31 & Yes \\
\hline Ana & 65 & Elementary & $\begin{array}{l}\text { Husband and } \\
\text { daughter }\end{array}$ & 17 & Yes \\
\hline Luís & 72 & Elementary & Wife & $\begin{array}{l}\text { Do not } \\
\text { know }\end{array}$ & Yes \\
\hline Madalena & 63 & Elementary & Husband & 11 & Yes \\
\hline Rafael & 67 & Elementary & Alone & $\begin{array}{l}\text { Do not } \\
\text { know }\end{array}$ & Yes \\
\hline Miguel & 69 & Elementary & $\begin{array}{l}\text { Wife and } \\
\text { daughter }\end{array}$ & 16 & Yes \\
\hline \multicolumn{6}{|l|}{ Disruption } \\
\hline António & 41 & High & Wife and son & 5 & Yes \\
\hline João & 64 & High & Wife & 10 & Yes \\
\hline Nuno & 71 & High & Alone & 2 & Yes \\
\hline Margarida & 37 & High & $\begin{array}{l}\text { Husband and } \\
\text { son }\end{array}$ & 5 & Yes \\
\hline
\end{tabular}

For me diabetes was like some other disease, just like the flu.

[Laura] a condition like any other disease. Some people have high cholesterol, others have hypertension. (...) So far, I have nothing that convinces me that it's that serious.

[Alice]
I was already expecting this [diabetes], because when you have your both parents as diabetics, someone (one of the siblings) will inherit it. My mother was always telling me: "you have to do blood tests. I inherited this from your grandfather!" And one of the times I did a blood test, turns out, it was positive. We just have to accept (...) For me it is
I am from a diabetic family. One of my brothers (diabetic) amputated half of his leg. He is 2 years younger than me, but I had another one [brother] that also amputated his leg, he was older than me but already passed away. And my other sister (also diabetic) amputated her foot. We 
inherited this from our parents. There's nothing we can do

(...) But my diabetes is minimal, I don't even need to take insulin.

[Isabel]

This minimisation of diagnosis contributes, in some cases, to the nonadherence to, or even absence of, medical treatment for a certain period, in particular when there are issues considered more important than diabetes, such as comorbidities or even financial commitments:

I'm very attached to my older son (...) and one Saturday (...) he didn't come home to sleep. I cried all night (with worry)! (...) He was all right, but that night I started to feel ill. I was so tired, my body hurt and then it (diabetes) began. (...) I didn't follow any treatment for many years, [because] I had other concerns, I had to work to pay my house.

[Beatriz]

\subsection{2 | Self-management skills}

The difficulties in adherence to changes of lifestyle are justified by three main arguments: absence of pain; the belief that "diabetes will never heal"; and lack of awareness about prognosis. Poor adherence is slightly improved when interviewees become aware of the chronicity of diabetes or of its worst consequences and complications. Afterwards, interviewees focus on prioritising adherence to medication, while showing difficulties in knowing how to properly follow the diabetic diet, and without referring to exercise as part of treatment. Participants attributed symbolic connotations to diabetes, as a way of reflecting their own understanding that it would not heal exclusively through medical intervention, such as, the idea of diabetes being a plague:

My sister usually tells me that bad things can happen [as consequences of diabetes]. But I am very confident (...) and I think I have everything controlled. At least, I feel no pain! [Lourenço]

I did the medication that my doctor prescribed me and I was ok. I could eat all I wanted, medication was enough. But now, I don't know why, I can't! It was never this bad. I can't eat anything, because it is always high (glycemic level). I lost $18 \mathrm{kgs}$ in the last months. For me diabetes is a plague, a plague! I have doubts about everything. (...) There are bad diseases, but if we treat ourselves we get better, (...) but not in diabetes. (...) When I was diagnosed I didn't think it was bad, I thought there was a cure. (...) But [now I know that] my diabetes will never heal.

[Laura]
Although these patients usually do not remember the names of the drugs and their specific purposes, they can describe the colours of the pills or boxes:

I take one pill in the morning and another in the evening. (...) I don't remember [the name]. It's a box, pink and white. It's a generic. She (the doctor) says it's for diabetes.

[Alice]

I can't tell you the name of the medication [doesn't know]. I take insulin now, and I take 13 pills a day [not only for diabetes but for other chronic conditions]. But I didn't start being medicated right away. I was diagnosed in France [31 years ago], and the doctor prescribed medication, but I didn't felt any pain, I was only tired... Life was hard back then. So, I didn't do anything.

[Beatriz]

\subsection{3 | Health literacy mediators}

Interviewees enacting a narrative of minimisation report the largest number of literacy mediators (Figure 1-Group 1), mainly health professionals they usually interact with (doctor, nurses and chemist) and also family members with type 2 diabetes or living in the same household.

They search information about diabetes mainly inside their formal one-way doctor/patient relationship, revealing high levels of trust on their own doctors-responsible for prescribing medication or treatments. They also state that the nurses working at the health centre where they usually are treated as important for managing the condition, controlling blood sugar or feet care:

I pay high, high attention to what the doctor says. I try to follow his advices, to walk a little, but I don't do it that often, once in a while I walk with my dog. Usually it is the nurse that tests my glucose, when I came to the medical visit. And that's it. I have the machine and everything, but I don't do it [control blood sugar] ... well, maybe I don't want to get used to it. (...) I understand nothing of that [glucose levels]! I ask the doctor if it's good or bad, that's all I need to know.

[Júlio]

Informal support is provided by family and friends, usually those sharing from the same condition, and relies on sharing experiences, as well as help in decision-making about treatments and changes in daily routines. Besides this, the responsibilities of the significant other (caregiver) include management of medication (e.g. organising the pill boxes) or controlling diet: 


\section{GROUP 1}

\section{$N=12 / 26$}

HEALTH PROFESSIONALS

FAMILY \& FRIENDS

MEDIA
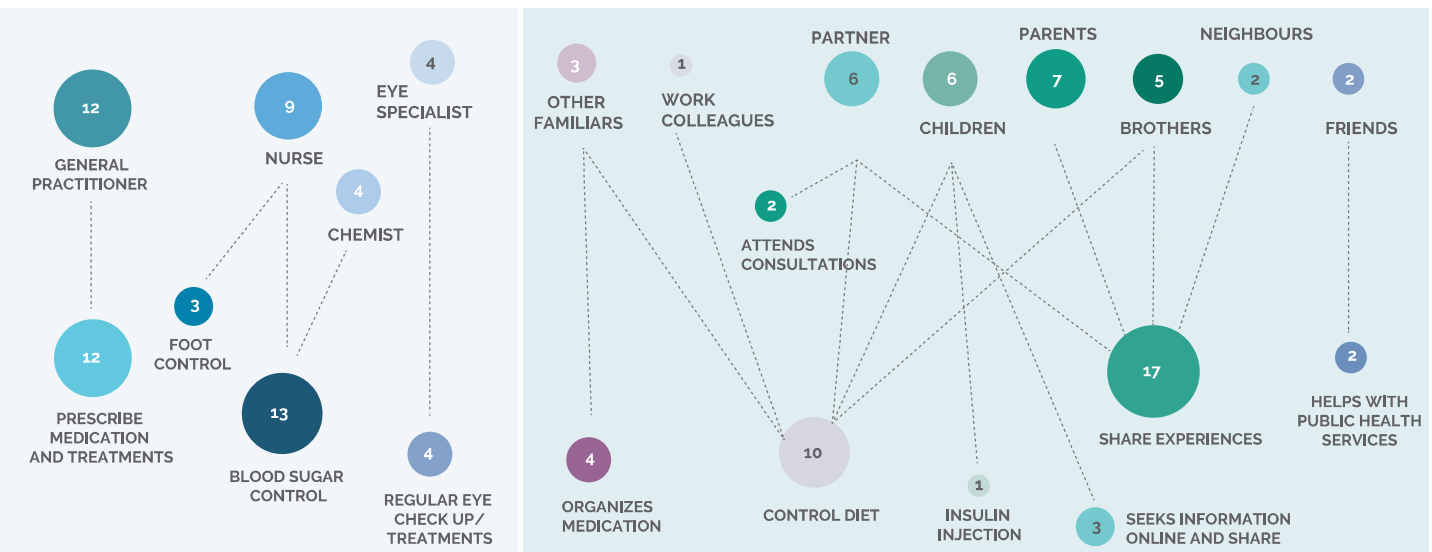

\section{GROUP 2}

\section{$N=10 / 26$}

HEALTH PROFESSIONALS

FAMILY \& FRIENDS

1

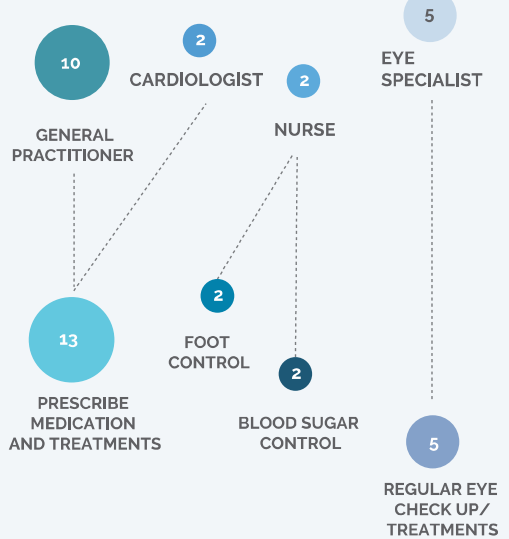
NUTRITIONIST

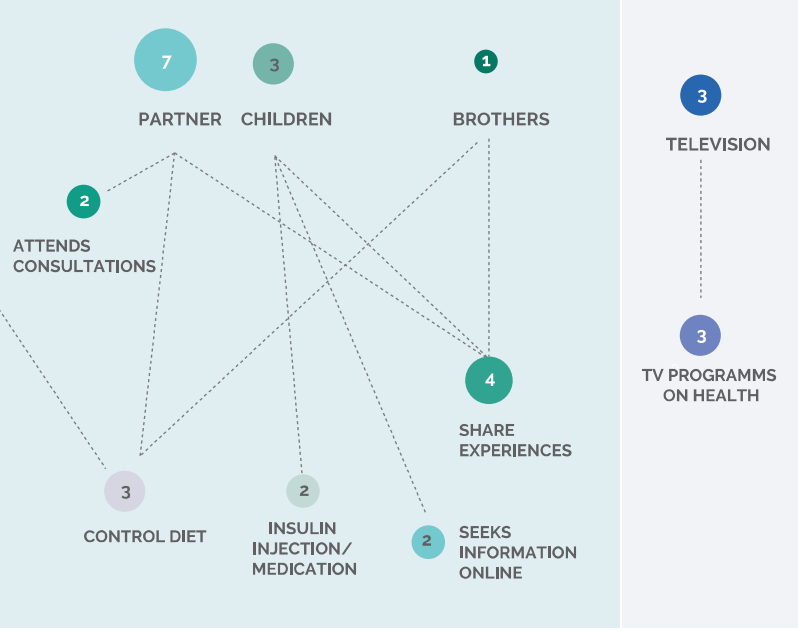

\section{GROUP 3}

\section{$N=4 / 26$}

HEALTH PROFESSIONALS

FAMILY \& FRIENDS

-

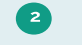

PARENTS PRACTITIONER
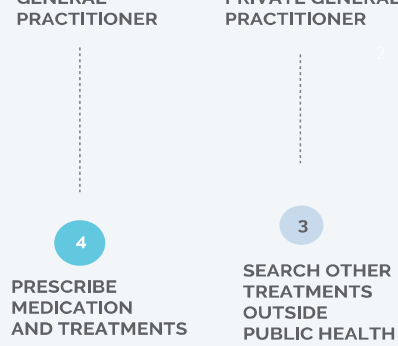

\section{3}

SEARCH OTHER TREATMENTS OUTSIDE PUBLIC HEALTH SERVICE AND TREATMEN

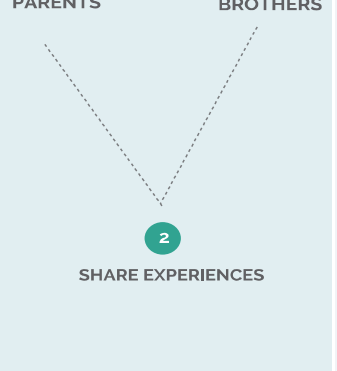

2

TELEVISION
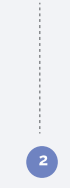

TV PROGRAMMS ON HEALTH

MEDIA

FIGURE 1 Map of health literacy mediators and practices divided into three groups. Note. Circles are the frequency that each mediator was mentioned and lines are the association with different health literacy practices. [Colour figure can be viewed at wileyonlinelibrary.com] 
My granddaughter puts all my pills in a small box (with divisions) like that: in the morning; after breakfast; lunch; and in the evening. I just go there and pick them. (...) When I need something, I just tell her: "I need this, that and that, please come here that I need you to see something for me." I just call for my granddaughter (...) and she comes.

[Beatriz]

I cannot say that I control myself $100 \%$ (in terms of diet), but my wife pays more attention to that and often she boils something for me, like potatoes, fish, or something healthier. And she cooks something else for her. (...) Also, when my sister comes to visit me, she usually gives me advices (she has been diabetic for a longer period of time) and Ilearned from her.

[Lourenço]

When I speak with other diabetics, like my father, and they tell me their glycemic levels and I tell them mine, those who usually have high glycemic levels frequently say to me: "Oh, that's not diabetes!" My diabetes are not the bad ones.

[César]

I don't have the freedom I used to have. Two weeks ago, my glycemic levels were permanently above 300, I couldn't control it. I was desperate because I didn't know what I was doing wrong. My daughter tried to help. She came to change my sticks from the machine. She wanted to know if with new ones things would get better. And they did.

[Hugo]

\section{2 | Group 2. Narrative of empathy}

\subsection{1 | Dealing with the diagnosis}

Interviewees enacting a narrative of empathy mention readjustments in their lives after the diagnosis of diabetes, including the strict following of medical treatments and recommendations, and how they empathically self-identify as a person with the condition of diabetic.

In this group, diagnosis is a starting point for the process of sensemaking of previous symptoms. These patients embed the diagnosis of diabetes in an interpretative approach, providing satisfactory explanatory models that span lay and professional knowledge. They try to search for causes, through explanatory models about individual lifestyles trajectories, as a pathway to understanding and empathically deal with the diagnosis:
At the moment of diagnosis, the doctor explained to me what diabetes was, and told me to control it every day. We talked about all the recommendations I had to follow. And 3 months after this appointment, I had my second visit and I told the doctor:" It's done. That's it, my diabetes is where I want it to be. I'm adjusted to it".

[Rafael]

For more than 30 years I worked in a construction company, we worked in many different places in the world, and all our meals were made at the company canteens (...) And you know how canteens food is, rice or pasta every single day. I think that diabetes was being created all those years of bad diets. That's how diabetes appeared in my life.

[Miguel]

I had no idea what diabtes was No idea! I only used to feel very thirsty, my mouth was always very dry. I wondered what that could be? Then I told the doctor about the symptoms and he (...) asked me to have a blood test. (...) I thought I also had bronchitis: "Could it be from bronchitis? Could it be from sleeping with my mouth open?"

[Luís]

\subsection{2 | Self-management skills}

The interviewees enacting a narrative of empathy are aware of the main components of self-managing diabetes-medication, diet and exercise-but attribute more importance to adherence to medication. They identify the names and purposes of drugs, despite difficulties in pronouncing their names, and have sufficient knowledge of what is proper diabetic diet, although they reveal difficulties in complying with it. Following a "diabetic diet" is a biggest difficulty they have, even being aware of the harm of not complying with it. Miguel, for example, feels pressure to get to like what he can eat while being unable to eat what he would like:

Now I take Brizidon, I take Vizicor for cholesterol; I take Tramolit for the thromboses; I take Atacan for blood pressure, and nothing else. For pressure, I take Atacan in the morning with the Brizidon for the "devils" (in Portuguese "diabretes" $\approx$ diabetes) (...) I eat fish, lots of fish, but it is not "that" diabetic diet [recommended by the doctor]. (...) If I am eating my diet and next to me there's a colleague eating (some other food), I start looking at him, and not at my food, my eyes don't stop viewing his food! Because mine doesn't have any taste, nothing.

[Miguel] 
While medication and diet are directly connected to the control of glucose levels, exercise combined with diet is described as a way of feeling healthier. In addition, exercise is described as a "tool" to lower glycemic levels and to eat beyond the strict diabetic diet:

At the end of the month I will have an appointment with a nutritionist. She usually tells me I can't eat this or that, but I am aware of those things. If I want to eat more, I know that if, before the meal, I go to my backyard to dig a little or make some physical exercise, I can eat more things that I like.

[Henrique]

The doctor told me to walk every day, and I walk every single day, 6-7 kms. When I feel a little dizzy I know if it is because I walked too much and did too much effort or the opposite. I know right away what it is. I view my glycemic levels (just to confirm), and there it is. So, I immediately do something to stabilised glucose, usually with hiking. I walk a lot, I just need to do some physical exercise and things get better.

[Luís]

\subsection{3 | Health literacy mediators}

This group has an intermediate number of health literacy mediators (Figure 1-Group 2), and relationships with health professionals are described as two-way communication. Most of the information, doubts and concerns patients have are shared in consultations with doctors, and treatments are "negotiated." These interviewees are aware of when medication does not "work" properly and are sensitive to symptoms caused by it.

I know very well the medication and the effects. For example, one medication, Lasix, I used to take it in the morning but I stayed so bloated with that. I could not go anywhere, because I have to go to the bathroom every hour. So, I decided only take it in the afternoon, so like that I can do things during the day. But those are my conclusions! The doctor once tried to change to a generic, but it was such a mess, I felt very badly, I didn't adapt to it. (...) We discussed the situation and stopped all generic medication.

[Helena]

Media may function as a source of empowerment for some participants, specifically those with accessible language and images, easy to understand:

I've watched so many things (on TV) and people speaking about diabetes also! But usually they mention diabetes at an advanced stage. (...) I see every day the programme from TV Globo about health, and I have learned so many things not only about diabetes. The eyes, the nose, the throat, they explain everything so well. I understand everything, I see my symptoms.

[Carla]

Although individual use of the Internet is rare, participants frequently comment that someone close to them (e.g. son or daughter) search information about diabetes on the Internet. Diabetes tends to be managed by all household members, who provide information about diet, interpretation of symptoms or help with medication:

My wife was diabetic (she past away), and so is my son. Once my doctor prescribed one medication and I didn't feel good after taking it, it had no effect. My son told me to stop taking it and I told that to my doctor: "Doctor what if I would change medication? You are the expert but this medication does not let me feel well". And he did change my medication.

[Isaac]

My son goes to the internet (to search for health information), and I don't like him always telling me the same. He is always saying: "This is bad for you, don't eat it! This is for your own good!"

[Carla]

I have two scissors: my wife and my daughter. (...) When we go dinner out, which is not very common, but first thing they say is: "Be careful with what you eat!" Yes, yes, they help me. My daughter always gets the pills I am going to take.

[Miguel]

\section{3 | Group 3. Narrative of disruption}

\subsection{1 | Dealing with the diagnosis}

Interviewees tend to recall the diagnosis as a disruptive moment, after which they become self-aware of being at risk. António, for example, describes such a moment as an emotional roller-coaster that caused panic, anxiety and uncertainty:

After being diagnosed, I felt so bad, I dealt very bad with the news. Never nobody warned me for this! For 3 months, [I felt] panic, anxiety, (...) I thought I was going to die! (...) Being diagnosed with diabetes type 2 at 36, 37 years, is too scary! (...). It was a stone falling on my head. 
They display understanding of health information and use technical language, as illustrated by Nuno's explanation of how the diagnosis of diabetes is done:

I don't know if you know, but a diagnosis of diabetes is made through routine glycemic level control, if it is higher than that cut off point. Probably with all prevention programmes, that will change in the future, but now it is done like this.

[Nuno]

After the diagnosis, patients search for detailed information about diabetes in several sources. This behaviour is described as having facilitated the acceptance of diabetes and the return to normalisation through a "restitution narrative"-when they assimilate and adapt their routines to their condition:

At the time [of diagnosis], I was reassured by the doctor and I started the medication. Gradually I started to be interested [in knowing more about diabetes]. I studied diabetes, went to conferences, read papers. I tried to find solutions, it was not easy for me to deal with this. Because I didn't want to depend on a medication for the rest of my life. Gradually, I accepted it better.

[João]

I was not shocked with the diagnosis. I was shocked that the doctor did not speak about it! I mean, the context (...) I felt that for every question I have asked (in the diagnosis consultation), he (the doctor) did not like that I asked. So, I manage the situation and I look for another doctor loutside public service) to have a counterpoint.

[Nuno]

\subsection{2 | Self-management skills}

Interviewees tend to feel confident to manage diabetes autonomously, and believe that suitable lifestyles, namely exercise and diet, will be enough to manage diabetes in the future. Compliance with medication is mentioned as the first recommendation to be "avoided". Patients' worries about side effects of medication lead them to seek the glycemic control only through diet and exercise, placing the responsibility to avoid medication in themselves. If they do not succeed in controlling glycemic levels without medication, it is only then that they take it:

My yearning is to be able to reach the moment when just with a healthy diet and this lifestyle (daily exercise) I will no longer need medication, and I almost can do that. I don't want to be dependent on medication, it makes me feel bad. Also, I am aware of the real costs of this kind of medication, and I think that the way things go, one day I will have to pay that totally by myself, because there will be no public money to support this. At that moment, I surely don't want be dependent on this medication, it is too expensive.

[João]

Because I studied the condition ... I saw my levels and I'm really on the borderline of being non-diabetic, it is such a tiny difference. (...) I prefer that someone tells me: "go do exercise, go upstairs and down" than "take this medication". I know that some doctors prefer that way. So, the main responsibility was and is mine.

[Nuno]

\subsubsection{Health literacy mediators}

This group has the smallest number of health literacy mediators: first, family doctor and Internet; second, private family doctor; and lastly, family members (Figure 1-Group 3). The use of such sources of information other than health professionals tends to lead into a critical literacy and to finding alternative solutions for improving their health condition:

I have a very scientific approach when I'm studying something, I go deep into the subject. And I did a 3 months diary about my daily diet. I already have done it for my mother, when she had Alzheimer's. (...) It helped my mother, and know it helps me to control diabetes (without medication). It's a way of controlling and trying to figure out what it is the best way to control glucose levels.

[Nuno]

These interviewees feel the need of studying to disseminate information and advice to others, specifically the closest, as Nuno states:

I am the type of person who likes to go deeper, to retain and summarise the more important, in order to spread it through my children and family members: "look, this is my experience ... take care" something like that.

[Nuno]

Additionally, worries with diet determine major lifestyle changes, such as becoming vegetarian and even organising workshops on vegetarian diet, under the assumption that it is beneficial for diabetes. In addition, vegetarianism is seen as a way of helping healthy people, who might be at risk from becoming diabetic, to have a healthier lifestyle:

I believe it is better not only for diabetes but for a healthy lifestyle.

[Margarida] 


\section{DISCUSSION}

This study demonstrates that exploring meanings given to diagnosis, identifying health mediators and analysing the structure of social networks, in particular shared practices and responsibilities, can contribute to understand the distributed nature of health literacy. The acknowledgement of the distributed nature of health literacy provides complementary information about the influence of social networks to a more sustainable patient-centred care. Moreover, our findings also determine that social networks act both as "systems of support" and as critical sponsors to diabetic's self-management, dimensions already discussed and recognised in previous studies (Foss et al., 2015; Rogers et al., 2011; Vassilev et al., 2013).

Diagnosis of diabetes emerges as a critical starting point of the communication process of becoming a literate patient. The minimisation of diagnosis (Group 1) translates into resignation towards what are believed to be "inevitable" consequences of the diagnosis of diabetes and is more frequent among people with lower education levels, while disruption (Group 3) gives rise to navigate in the health system searching for alternatives (e.g. managing diabetes without medication, just through healthy lifestyles), being more common in persons with high levels of education. The narrative of empathy (Group 2) reflects the "good patient" (Jadad, 2003) whose attitude towards diagnosis appears as positively linked to the incentive to act according to the recommendations of health professionals, especially when prioritising medication. As Brown (1987, 1990, 1995) and Jutel (2011) argued, exploring the perspectives and experiences associated with a diagnosis provides an important insight into how people understand and recognise disease, illness and health, shaping their knowledge and practices regarding patient-doctor interaction, pharmaceuticalisation, self-management and disease acceptance.

Those who tend to minimise diagnosis rely on a broader network of mediators with a high number of interactions, making the management of diabetes more complex. In this context, the disclaimer of responsibility for self-management and inconsistent information or conflicting advice are more likely to occur, specially within mediators with low levels of health literacy, potentially influencing the health outcomes of the patient (Garcia, Espinoza, Lichtenstein, \& Hazuda, 2013; Yuen, Knight, Ricciardelli, \& Burney, 2016). It is then important to articulate the tapestry that composes this frame of different skills by considering the distribution of responsibilities among all the mediators beyond the emphasis on individual patient's responsibility. Benefits are to be expected when people have health mediators and adequate social support to the management of type 2 diabetes (American Diabetes Association, 2014; Fisher et al., 2012; Rothschild et al., 2014; Thom et al., 2013; Gagliardino et al., 2013; Smith et al., 2011; Dale, Williams, \& Bowyer, 2012; Zhang, Yang, Sun, Fisher, \& Sun, 2016; Finset, 2015), according to their own needs and life circumstances: individuals in Group 1 (narrative of minimisation) need "basic" health information, helping directly in daily tasks, while those belonging to Group 2 (narrative of empathy) need help to understand health information and receive emotional support to pursue healthy behaviours, such as helping them pursue a healthy diet, as a most meaningful simple act of caring; and Group 3 (narrative of disruption) need to have access to a more detailed and formal information about diabetes in order to prevent the emotional roller-coaster that diagnosis of diabetes might otherwise lead to.

The DHL of each individual may reflect a blend of their illness identity, as a result of life trajectories and consequent meanings given to diagnosis, unveiled in the restitutive narratives. These narratives are the result of accepting, mastering or adapting illness to normal life course (Finset, 2015), as well as a synonym of the burden that selfmanagement practices might represent for patients and also, as Sav et al. (2013) noted, to their careers.

The complexity and heterogeneity of the $\mathrm{DHL}$ can be teased apart by examining how people deal with diagnosis and how the support from all mediators involved in the network interact with their selfmanagement skills. Partially consistent with results of other study that focus the influence of social networks and social support in chronic conditions self-care (Gunn, Seers, Posner, \& Coates, 2012; Koetsenruijter et al., 2016), our study has shown DHL to be significantly important to assure a proper illness self-management, filling the gap that individual health literacy leaves open.

These findings are, however, limited by the sample size and the cross-sectional nature of the study design, not being able to assess behaviour changes through time, as well as gendered narratives of the experience of care or self-management of diabetes. Recall bias may have also influenced interviewees' narratives, as patients recalled experiences extending as far back as to diagnosis, from 30 years ago to 2 years.

\section{5 | CONCLUSION}

Meanings given to diagnosis-disruption, empathy and minimisationwere associated, respectively, with a growing individual network of literacy mediators and shared practices of each patient, contributing to a deeper understanding of the distributed nature of health literacy. The influence of a network of family, friends, media and health professionals providing mainly informational support was particularly strong when patients had lower educational levels.

$\mathrm{DHL}$ can fill the gap left open by an emphasis on individual health literacy, showing that a strong, articulated and oriented network of health literacy mediators might compensate the adverse effects of low levels of literacy. To take into account the transfer of acquired skills and patient support by each social network would facilitate the encouragement of patient-centeredness and the understanding of clinical relationships partnerships.

\section{1 | Implications for practice}

This study shows how the involvement of multiple mediators in each individual networks contributes to different health literacy practices. It is necessary to create hybrid spaces for dialogue between them to activate empowered attitudes. For example, spaces should be constructed for patients to ask more questions and 
participate in more informed health-decision-making discussions. Research on health systems that aim to develop new or improve on existing models, in order to make them more patient-centred, should give attention to patients' DHL rather than just emphasising individual health literacy capabilities. This implies giving particular attention to the way patients deal with diagnosis, identify the mediators and clarify the distribution of capabilities and responsibilities in the network.

\section{ACKNOWLEDGEMENTS}

We are grateful to staff members of the Primary Care Center, for their assistance in recruiting research participants, and to all participants for their generosity in sharing their time and experiences. We also thank Anabela Nunes (Communication Unit, i3S-Instituto de Inovação e Investigação em Saúde) for her precious help on the design of Figure 1.

\section{CONFLICTS OF INTEREST}

No conflicts of interest are declared.

\section{REFERENCES}

Abreu, L., Borlido-Santos, J., Vilar-Correia, M. R., \& Arriscado-Nunes, J. (2012). Modos de apropriação de informação sobre saúde: Adaptação de um instrumento de investigação qualitativa. Porto: VII Congresso Português de Sociologia.

American Diabetes Association (2014). Diagnosis and classification of diabetes mellitus. Diabetes Care, 37, S81-S90.

Anderson, R. M. (1985). Is the problem of compliance all in our heads? Diabetes Education, 11, 31-34.

Andrus, M. R., \& Roth, M. T. (2002). Health literacy: A review. Pharmacotherapy, 22, 282-302.

Baynham, M. (1995). Literacy practices: Investigating literacy in social contexts. Studies in Second Language Acquisition, 18(3). https://doi. org/10.1017/S027226310001531X.

Berkman, N. D., Davis, T. C., \& McCormack, L. (2010). Health literacy: What is it? Journal of Health Communication, 15, 9-19.

Brown, P. (1987). Diagnostic conflict and contradiction in psychiatry. Journal of Health and Social Behavior, 28, 37-50.

Brown, P. (1990). The name game: Toward a sociology of diagnosis. Journal of Mind and Behavior, 11(3-4), 385.

Brown, P. (1995). Naming and framing: The social construction of diagnosis and illness. Journal of Health and Social Behavior, 34-52.

Bryant, A., \& Charmaz, K. (2010). The SAGE handbook of grounded theory. Thousand Oaks, CA: SAGE.

Bury, M. (2001). Illness narratives: Fact or fiction? Sociology of Health and Illness, 23, 263-285.

Charmaz, K. (1983). The sociology of chronic illness: A review of research and prospects. Sociology of Health \& Illness, 13, 451-468.

Clement, S., Ibrahim, S., Crichton, N., Wolf, M., \& Rowlands, G. (2009). Complex interventions to improve the health of people with limited literacy: A systematic review. Patient Education and Counseling, 75, 340-351.

Coulter, A., Parsons, S., \& Askham, J. (2008). Where are the patients in decision-making about their own care? 14. Retrieved from http:// www.who.int/management/general/decisionmaking/Where ArePatientsinDecisionMaking.pdf.
Dale, J. R., Williams, S. M., \& Bowyer, V. (2012). What is the effect of peer support on diabetes outcomes in adults? A systematic review. Diabetic Medicine, 29, 1361-1377.

Edwards, M., Wood, F., Davies, M., \& Edwards, A. (2012). The development of health literacy in patients with a long-term health condition: The health literacy pathway model. BMC Public Health, 12, 130.

Edwards, M., Wood, F., Davies, M., \& Edwards, A. (2013). "Distributed health literacy": Longitudinal qualitative analysis of the roles of health literacy mediators and social networks of people living with a longterm health condition. Health Expectations, https://doi.org/10.1111/ hex.12093.

Elissen, A., Nolte, E., \& Knai, C. (2013). Is Europe putting theory into practice? A qualitative study of the level of self-management support in chronic care management approaches. BMC Health Services Research, 13, 117.

Finset, A. (2015). How can we promote patient recall of information from medical consultations? Patient Education and Counseling, 98, 683-684.

Fisher, E. B., Boothroyd, R. I., Coufal, M. M., Baumann, L. C., Mbanya, J. C., Rotheram-Borus, M. J., ... Tanasugarn, C. (2012). Peer support for selfmanagement of diabetes improved outcomes in international settings. Health Affair, 31, 130-139.

Flyvbjerg, B. (2006). Five misunderstandings about case-study Research. Qualitative Inquiry, 12, 219-245.

Foss, C., Knutsen, I., Kennedy, A., Todorova, E., Wensing, M., Lionis, C., ... Rogers, A. (2015). Connectivity, contest and the ties of selfmanagement support for type 2 diabetes: A meta-synthesis of qualitative literature. Health and Social Care in the Community, https://doi. org/10.1111/hsc.12272.

Gagliardino, J. J., Arrechea, V., Assad, D., Gagliardino, G. G., González, L., Lucero, S., ... Clark, C. Jr. (2013). Type 2 diabetes patients educated by other patients perform at least as well as patients trained by professionals. Diabetes/Metabolism Research, 29, 152-160.

Garcia, C. H., Espinoza, S. E., Lichtenstein, M., \& Hazuda, H. P. (2013). Health literacy associations between Hispanic elderly patients and their caregivers. Journal of Health Communication, 18(Suppl. 1), 256-272.

Greenhalgh, T. (2009). Chronic illness: Beyond the expert patient. British Medical Journal, 338, 629-631.

Groleau, D., Young, A., \& Kirmayer, L. (2006). The McGill Illness Narrative Interview (MINI): An interview schedule to elicit meanings and modes of reasoning related to illness experience. Transcultural Psychiatry, 43, 671-691.

Gunn, K. L., Seers, K., Posner, N., \& Coates, V. (2012). 'Somebody there to watch over you': The role of the family in everyday and emergency diabetes care. Health and Social Care in the Community, 20, 591-598.

Jadad, A. (2003). I am a good patient, believe it or not. British Medical Journal, https://doi.org/10.1136/bmj.326.7402.1293.

Jutel, A. (2011). Putting a name to it: Diagnosis in contemporary society. Baltimore: John Hopkins University Press.

Koetsenruijter, J., Eikelenboom, N., Lieshout, J., Vassilev, I., Lionis, C., Todorova, E., ... Wensing, M. (2016). Social support and selfmanagement capabilities in diabetes patients: An international observational study. Patient Education and Counseling, 99, 638-643.

Kousoulis, A., Patelarou, E., Shea, S., Foss, C., Knutsen, I. A., Todorova, E., ... Lionis, C. (2014). Diabetes self-management arrangements in Europe: $A$ realist review to facilitate a project implemented in six countries. BMC Health Care Services Research, 14, 453.

Lee, S., Arozullah, A. M., \& Cho, Y. I. (2004). Health literacy, social support, and health: A research agenda. Social Science and Medicine, 58, 1309-1321.

Lepore, S. J. (1991). Dynamic role of social support in the links between chronic stress and psychological distress. Journal of Personality and Social Psychology, 61, 899-909.

Mantwill, S., \& Schulz, P. J. (2015). Low health literacy associated with higher medication costs in patients with type 2 diabetes mellitus: Evidence from matched survey and health insurance data. Patient Education and Counseling, 98, 1625-1630. 
Miller, T. A. (2016). Health literacy and adherence to medical treatment in chronic and acute illness: A meta-analysis. Patient Education and Counseling, https://doi.org/10.1016/j.pec.2016.01.020.

Nielsen-Bohlman, L., \& Institute of Medicine (U.S.). (2004). Health literacy: A prescription to end confusion. Washington, DC: National Academies Press.

Nutbeam, A. (2000). Health literacy as a public health goal: A challenge for contemporary health education and communication strategies into the 21st century. Health Promotion International, 15, 259-267.

Osborn, C., Bains, S. S., \& Egede, L. E. (2010). Health literacy, diabetes self-care and glycemic control in adults with type 2 diabetes. Diabetes Technology and Therapeutics, 12, 913-919.

Pooley, C. G., Gerrard, C., Morton, S., \& Astbury, J. (2001). "Oh its a wonderful practice ... you can talk to them": A qualitative study of patients' and health professionals' views on the management of type 2 diabetes. Health and Social Care in the Community, 9, 318-326.

Powell, C. K., Hill, E. G., \& Clancy, D. E. (2007). The relationship between health literacy and diabetes knowledge and readiness to take health actions. Diabetes Education, 33, 144-151.

Rogers, A., Vassiliev, I., Sanders, C., Kirk, S., Chew-Graham, C., Kennedy, A., ... Richardson, G. (2011). Social networks, work and network-based resources for the management of long-term conditions: A framework and study protocol for developing self-care support. Science, 6, 56.

Rothschild, S. K., Martin, M. A., Swider, S. M., Tumialán, L. C. M., Janssen, I., Avery, E. F., \& Powell, L. H. (2014). Mexican American trial of community health workers: A randomized controlled trial of a community health worker intervention for Mexican Americans with type 2 diabetes mellitus. American Journal of Public Health, 104, 1540-1548.

Russo, J. R., \& Walker, E. A. (2001). Adherence to treatment in. Diabetes, 29-35.

Sav, A., Kendall, E., McMillan, S. S., Kelly, F., Whitty, J. A., King, M. A., \& Wheeler, A. J. (2013). 'You say treatment, I say hard work': Treatment burden among people with chronic illness and their careers in Australia. Health and Social Care in the Community, 21, 665-674.

Smith, S., Paul, G., Kelly, A., Whitford, D. L., O'Shea, E., \& O'Dowd, T. (2011). Peer support for patients with type 2 diabetes: Cluster randomised controlled trial. British Medical Journal, 342, d715.

Sontag, S. (1978). Illness as metaphor. New York: Farrar, Strauss and Giroux.
Sørensen, K., Broucke, S., Fullam, J., Doyle, G., Pelikan, J., Slonska, Z., \& Brand, H. (2012). Health literacy and public health: A systematic review and integration of definitions and models. BMC Public Health, 12, 80.

Strauss, A., \& Corbin, J. (1998). Basic of qualitative research: Techniques and procedures for developing grounded theory. London: Sage.

Thom, D. H., Ghorob, A., Hessler, D, De Vore, D., Chen, E., \& Bodenheimer, T. A. (2013). Impact of peer health coaching on glycemic control in lowincome patients with diabetes: A randomized controlled trial. Annals of Family Medicine, 11, 137-144.

Vassilev, I., Rogers, A., Blickem, C., Brooks, H., Kapadia, D., Kennedy, A., ... Reeves, D. (2013). Social networks, the 'work' and work force of chronic illness self-management: A survey analysis of personal communities. PLoS ONE, https://doi.org/10.1371/journal.pone.0059723.

Williams, M. V., Baker, D. W., Parker, R. M., \& Nurss, J. R. (1998). Relationship of functional health literacy to patients' knowledge of their chronic disease: A study of patients with hypertension and diabetes. Archives of Internal Medicine, 158, 166-172.

Williams, M. V., Parker, R. M., Baker, D., Parikh, N. S., Pitkin, K., Coates, W. C., \& Nurss, J. R. (1995). Inadequate functional health literacy among patients at two public hospitals. Journal of the American Medical Association, 274(1995), 1677-1682.

Yuen, E. Y. N., Knight, T., Ricciardelli, L. A., \& Burney, S. (2016). Health literacy of caregivers of adult care recipients: A systematic scoping review. Health and Social Care in the Community, https://doi.org/10.1111/ hsc. 12368.

Zhang, X., Yang, S., Sun, K., Fisher, E. B., \& Sun, X. (2016). How to achieve better effect of peer support among adults with type 2 diabetes: A meta-analysis of randomized clinical trials. Patient Education and Counseling, 99, 186-197.

How to cite this article: Abreu L, Nunes JA, Taylor P, Silva S. Distributed health literacy among people living with type 2 diabetes in Portugal: Defining levels of awareness and support. Health Soc Care Community. 2018;26:90-101. https://doi. org/10.1111/hsc.12465 